\title{
界面特性を考慮した異方性弾性論による ナノスケール異材接合体の特異応力場解析
}

\section{古口 日出男 ${ }^{* 1}$, 田中 悠介 ${ }^{* 2}$ \\ Analysis of singular stress field in nanoscaled dissimilar material joints using the anisotropic elasticity theory considering interface properties}

\author{
Hideo KOGUCHI ${ }^{* 1}$ and Yusuke TANAKA ${ }^{* 2}$ \\ ${ }^{* 1}$ Department of Mechanical Engineering, Nagaoka University of Technology \\ 1603-1 Kamitomioka-machi, Nagaoka-shi, Niigata 940-2188, Japan \\ ${ }^{* 2}$ Ajinomoto Frozen Foods Co., Inc. \\ 7-14-13 Ginza, Chuo-ku, Tokyo 104-0061, Japan
}

Received: 17 August 2016; Revised: 4 October 2016; Accepted: 13 December 2016

\begin{abstract}
In recent advanced semiconductor products, elements of thickness and width are frequently in nanoscale. As the size of elements reduces to nanometer, a ratio of surface to volume increases. Surface properties, such as surface stresses and surface elasticity, influence on the distributions of bulk stresses near the surface. In the present study, the singular stress at the corner in an anisotropic two-dimensional multi-wedge joint consisting of three kinds of material is analyzed using molecular statics (MS) method and the anisotropic elasticity theory with a boundary condition considering interface properties. The joints are composed of $\mathrm{Ni}, \mathrm{Au}$ and $\mathrm{Cu}$. Several joints with different wedge angles at the interface are analyzed. Distributions of atomic stress calculated by the MS method are compared with those by the theory. In the results of the MS analysis, stress jumps exist at the interface in the circumferential direction of the stress distribution around the stress singular point. It is supposed that these are attributed to the influence of interface stresses. Then, interface stresses and elastic properties at the interfaces are investigated using the MS method. The obtained interface properties are used in the stress analysis using the Stroh's formalism. Finally, the theoretical analysis considering the interface properties can be expressed the jumps of stress at the interfaces.
\end{abstract}

Key words : Molecular dynamics, Interface stresses, Interface elasticity, Interface corner, Stroh's formalism, Stress singularity

\section{1. 緒言}

近年，モバイル端末に代表される情報通信機器分野の高性能・小型・軽量化，さらに超高感度，高性能なセン サ，MEMS の開発が盛んに行われている，それらの製品にはカーボンナノファイバ，量子ドット，超薄膜，ナノ ワイヤなどのナノスケールの材料あるいは構造物が使用されている.これらの構造物は特性の異なる材料と接合 されて用いられることが多い. ナノスケールで表面あるいは界面を見ると, バルクと原子構造が異なっているこ とが知られている．体積に対する表面の比は，構造物が通常のマクロサイズでは小さいが，ナノサイズになると 大きくなり，表面の力学的特性がバルクの応力，変位分布に影響を与えると考えられる（Ibach, 1997, Muller and Saul, 2004, Duan et al., 2005a，2005b)．本論文の表面の力学的特性とは，表面エネルギに起因する表面応力および 表面弾性係数を指している（Hanbucken et al., 2011）。一般に，表面エネルギはひずみの関数であり，表面応力は 表面エネルギの表面ひずみによる一階微分から得られる。また，表面弾性係数は表面エネルギの表面ひずみによ る二階微分から得られる。通常，それらの量は分子静力学法などから得ることができる.これまでにも表面の力

\footnotetext{
No.16-00368 [DOI:10.1299/transjsme.16-00368], J-STAGE Advance Publication date: 26 December, 2016

*1 正員, フェロー, 長岡技術科学大学 工学部（干940-2188 新潟県長岡市上富岡町 1603-1)

*2 味の素冷凍食品（株）（干104-0061＼cjkstart東京都中央区銀座 7-14-13）

E-mail of corresponding author: koguchi@mech.nagaokaut.ac.jp
} 
学的特性を考慮に入れた関係式の応力解析への導入が行われている. Gurtin と Murdoch(1975)は理論的考察により 物体表面の表面応力と表面弾性を考慮した境界条件を導出した。 この際, 原子分子の議論はされず, 連続体力学 の境界条件として提案された. Gurtin と Murdoch の境界条件は，例えばThomson ら(1986), Kim ら(2010a, 2010b, 2011)のき裂先端近傍の忘力場の解析など, 多くの解析に用いられている. しかし, Gurtin らの境界条件は等方性 材料に対するものである．材料をナノスケールで見た場合，材料の異方性を考慮することが必要になってくる. 筆者らは連続体力学の拡張を目指し, マクロスケールの解析をナノスケールまで可能とする方法を研究している. 古口(1992)は Gurtin と Murdoch と別にナノサイズの弾性体の応力解析のために界面の運動および界面特性を考慮 した境界条件を新たに導出した，この境界条件は，異方性材料にも対応しており，表面波伝播，異材接合体の境 界条件に適用できる. 具体的にナノサイズ材料の応力解析に行うには, 異方性材料の表面応力, 表面弹性特性が 必要となる. これに関して, 泉ら (Izumi et al., 2004) は分子動力学法を用いて, シリコン(Si)表面の表面エネルギ, 表面応力, 表面弾性係数を求める方法を示した.

異材接合体に外力が作用する場合, 古典弾性論では接合界面端部には材料特性の違いによる応力特異場が発生 することが知られている(Bogy, 1971, Dempsey and Sinclair, 1979, Yang and Munz, 1997). 例えば, 界面端部に切欠き を有する接合体の引張り解析 (Labossiere and Dunn, 1999) やHwu ら(2003)の Stroh 形式を用いた異方性異材接合 体の解析, 堀池ら(2010)の分子静力学を用いた異材単結晶接合体の解析と異方性弹性体をあわせた解析等, 他多 数の研究がある. 応力特異場は接合体強度に影響を与えるため, 界面端における特異応力場がナノスケールでは どのように変化するのかを明らかにすることは，工学上・工業上有用であると考える．これまで，界面特性を考 慮した異方性異材接合体の特異応力場に対する解析は, Koguchi と Suzuki(2014)による研究以外ほとんど行われて いない. 古口らは，2 相異方性異材接合体における界面端の二次元特異応力場について, 界面特性を考慮して調 べた. その結果, 特異性のオーダが特異点からの距離の関数で表せること, さらに界面上の応力分布は特異点か らの距離の指数関数で，そのべき指数に解析で得られた特異性のオーダを用いて表せることを見いだした. 見か け上，界面特性を考慮していない場合の式と同じであるが，特異性のオーダが特異点からの距離の関数で变化す る点が異なる。一方，特異性のオーダを求める特性方程式が 2 相接合体に対応しており，多相接合体の場合に対 応していない. さらに, 特異点からの距離に対する特異応力場を主として調べており, 周方向の応力分布に対す る界面特性の影響はまだ明らかにされていない. そこで本研究では, 複数の材料からなる角部や薄膜の積層が行 われている箇所を想定し，〈さび形状を有する界面間の干渉効果もある 3 材料の異方性異材接合体に対して分子 静力学解析と界面特性を考慮した弾性論による応力場解析を行い, くさび領域の開き角が応力分布に及ぼす影響 を調べ，周方向の応力分布について弾性論との比較を行う.

\section{2. 解析方法}

\section{$2 \cdot 1 \quad M$ 相くさび型接合モデル}

はじめに，一般的な図 1 のような $M$ 個のくさび形状の領域からなる接合体を考える. 接合体のくさび領域の先 端を原点と寸る直交座標系 $x_{1}-x_{2}$ をとる. 座標系の原点は応力の特異点であり, 特異点からの距離を $r, x_{1}$ 軸から の角度を $\theta$ とする. この時, 特異応力場は次式のように表すことができる.

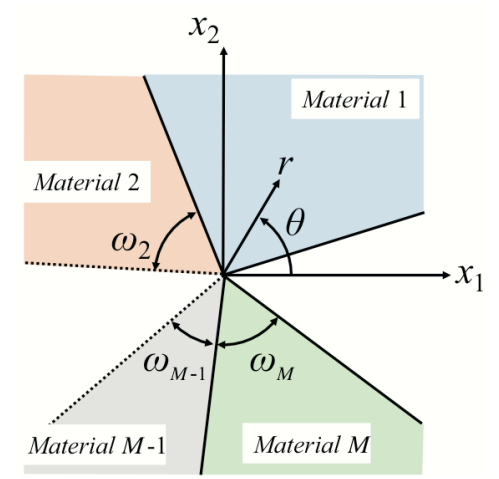

Fig.1 Multiwedge joints consisting of $M$-phase materials.

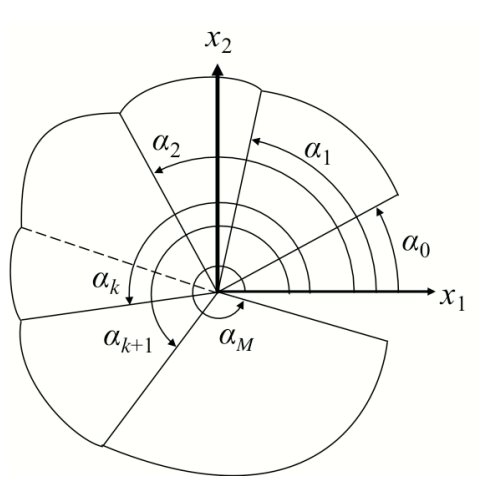

Fig. 2 Coordinate system with an origin at the wedge tip. 


$$
\sigma_{i j}^{(m)}=\sum_{l=1}^{L} K_{l} r^{-\lambda_{l}} f_{i j}^{l(m)}(\theta)
$$

ここで, $K_{l}$ は特異応力場の強さ, $\lambda_{l}$ は特異性のオーダ, $f(\theta)$ は角度関数である. $f(\theta)$ は材料定数と材料の開き角 $\omega$ により決定される。 $m$ は材料を表し, 図 1 では 1 から $M$ をとる.

このように, 界面角部先端近傍の応力成分は特異応力場の強さ, 特異性のオーダ, 角度関数が求まれば一意的 に表すことができる. よって, 界面角部を持つモデルの応力解析においては特異応力場の強さ, 特異性固有值, 角度関数を求めることが重要となる.

\section{$2 \cdot 2$ 界面特性を考慮した異方性接合体の固有方程式の導出}

ここでは, 界面特性を考慮した固有方程式を導き, ナノメータ接合体の特異場に関する式の誘導について概説 する. 誘導の詳細は既報（Koguchi and Suzuki, 2014）に示してあるので参照されたい.

異方性 2 次元弾性体の変位 $u_{\mathrm{i}}$ および応力 $\sigma_{\mathrm{ij}}$ は, Stroh 形式を用いると次式のように表すことができる (Hwu et al., 2003, Ting, 1996).

$$
\begin{aligned}
& \mathbf{u}=\mathbf{a} f(z), \quad \phi=\mathbf{b} f(z), \quad z=x_{1}+p x_{2} \\
& \sigma_{i 1}=-\phi_{i, 2}, \quad \sigma_{i 2}=\phi_{i, 1}
\end{aligned}
$$

ここで, $\phi$ は応力関数, $f(z)$ は変数 $z$ の任意の関数, $\mathbf{a}, \mathbf{b}$ は Stroh の固有ベクトル, $p$ は Stroh の固有值と呼ば れ，以下に示寸ように材料の弾性係数加求める.

弾性体の平衡方程式 $C_{\mathrm{ijks}} u_{\mathrm{k}, \mathrm{s}}=0$ から次式が得られる.

$$
\left\{\mathbf{Q}+p\left(\mathbf{R}+\mathbf{R}^{T}\right)+p^{2} \mathbf{T}\right\} \mathbf{a}=0
$$

ここで,

$$
Q_{i k}=C_{i 1 k 1}, \quad R_{i k}=C_{i 1 k 2}, \quad T_{i k}=C_{i 2 k 2}
$$

である．固有ベクトル $\boldsymbol{a}$ が非自明解を持つためには,

$$
\left|\mathbf{Q}+p\left(\mathbf{R}+\mathbf{R}^{T}\right)+p^{2} \mathbf{T}\right|=0
$$

を満たす必要があり, この式より固有值 $p$ が求まる.この式は $p$ の 6 次多項式で共役も含めると 3 つの異なる固 有值 $p_{j}$ と $\bar{p}_{j}(j=1,2,3)$ が得られる. ここで, 一は複素共役を表す. 求めた固有值 $p$ を式(4)に代入し固有べクト ル $\boldsymbol{a}$ を求める.また，応力・ひずみの関係式 $\sigma_{\mathrm{ij} j}=C_{\mathrm{ijk} s} u_{\mathrm{k}, \mathrm{s}}$ より

$$
\mathbf{b}=\left(\mathbf{R}^{T}+p \mathbf{T}\right) \mathbf{a}=-\frac{1}{p}(\mathbf{Q}+p \mathbf{R}) \mathbf{a}
$$

のようにb を求めることができる．それらの固有ベクトルを列ベクトルとする行列を次のように作る.

$$
\mathbf{A}=\left[\begin{array}{lll}
\mathbf{a}_{1} & \mathbf{a}_{2} & \mathbf{a}_{3}
\end{array}\right], \quad \mathbf{B}=\left[\begin{array}{lll}
\mathbf{b}_{1} & \mathbf{b}_{2} & \mathbf{b}_{3}
\end{array}\right]
$$

一般に異方性弾性体の平衡方程式を満たす解は次式のように書くことができる.

$$
\begin{aligned}
& \mathbf{u}=\mathbf{A f}(z)+\overline{\mathbf{A}} \overline{\mathbf{f}}(\bar{z}) \\
& \phi=\mathbf{B f}(z)+\overline{\mathbf{B}} \mathbf{f}(\bar{z})
\end{aligned}
$$

ここで， $\overline{\mathbf{A}} ， \overline{\mathbf{B}}$ は $\bar{p}$ に対する行列, $\mathbf{f}(\mathbf{z})=\left\{f_{1}\left(z_{1}\right) f_{2}\left(z_{2}\right) f_{3}\left(z_{3}\right)\right\}^{\mathrm{T}}, z_{k}=x_{1}+p_{k} x_{2}$ である.

つぎに, くさび領域の解を求めるため, $\mathbf{f}(z)=\operatorname{diag}\left[z_{1}^{\lambda} z_{2}^{\lambda} z_{3}^{\lambda}\right]=<z_{*}^{\lambda}>$ とおく. 図 2 のように極座標系の原点をと り, $x_{1}=r \sin \theta, x_{2}=r \cos \theta$ とすると，変位ベクトル，応力ベクトルはそれぞれ次式で与えられる.

$$
\begin{aligned}
& \mathbf{u}=r^{1-\lambda}\left\{\mathbf{A}\left\langle\hat{p}_{*}^{-\lambda}(\theta)\right\rangle \mathbf{g}+\overline{\mathbf{A}}\left\langle\overline{\hat{p}}_{*}^{-\lambda}(\theta)\right\rangle \mathbf{h}\right\} \\
& \mathbf{t}=(1-\lambda) r^{-\lambda}\left\{\mathbf{B}\left\langle\hat{p}_{*}^{-\lambda}(\theta)\right\rangle \mathbf{g}+\overline{\mathbf{B}}\left\langle\hat{\hat{p}}_{*}^{-\lambda}(\theta)\right\rangle \mathbf{h}\right\}
\end{aligned}
$$

ここで, $\hat{p}_{\alpha}(\theta)=\cos \theta+p_{\alpha} \sin \theta, \mathbf{g}$ と $\mathbf{h}$ は未知ベクトルである. 
図 2 の円柱座標系の変位 $\mathbf{u}_{c}$, 応力ベクトル $\mathbf{T}$ は次式のように表される.

$$
\begin{aligned}
& \mathbf{u}_{c}=\left\{\begin{array}{lll}
u_{r} & u_{\theta} & u_{3}
\end{array}\right\}^{T}=(\Omega(\theta) \mathbf{u})^{T} \\
& \mathbf{T}=\left\{\begin{array}{lll}
\sigma_{\theta r} & \sigma_{\theta \theta} & \sigma_{\theta 3}
\end{array}\right\}^{T}=\Omega(\theta) \mathbf{t}_{\theta}, \quad \mathbf{t}_{\theta}=\partial \phi / \partial r
\end{aligned}
$$

ここで, $\Omega(\theta)$ は次式で与えられる.

$$
\Omega(\theta)=\left[\begin{array}{ccc}
\cos \theta & \sin \theta & 0 \\
-\sin \theta & \cos \theta & 0 \\
0 & 0 & 1
\end{array}\right]
$$

以上の式を用いて図 2 の各くさび領域の解を求める.

まず界面特性を考慮した界面の境界条件について説明する. くさび領域 $k$ と $k+1$ が作る界面 $k$ における応力の 釣り合い式は次のように表される.

$$
\left\{\begin{array}{c}
\tau_{1 \beta, \beta}^{k} \\
\tau_{\mu \beta}^{k} \kappa_{\mu \beta}^{k} V_{2}^{k} \\
\tau_{3 \beta, \beta}^{k}
\end{array}\right\}+\left\{\begin{array}{c}
\sigma_{\theta r} \\
\sigma_{\theta \theta} \\
\sigma_{\theta 3}
\end{array}\right\}_{k+1}-\left\{\begin{array}{c}
\sigma_{\theta r} \\
\sigma_{\theta \theta} \\
\sigma_{\theta 3}
\end{array}\right\}_{k}=0
$$

ここで, \{\} の添え字はくさび領域の番号, $\kappa_{\alpha \beta}^{k}$ は界面 $k$ における曲率テンソルである.

接合体の場合, 界面特性が界面端の特異点からの距離 $r$ の任意の関数であると考え, 界面応力 $\tau_{\alpha \beta}$ を

$$
\tau_{\alpha \beta}=\tau_{\alpha \beta}^{0}(r)+d_{\alpha \beta \gamma \delta}^{0}(r) \varepsilon_{\gamma \delta}
$$

で表す．ここで， $\tau_{\alpha \beta}^{0} ， d_{\alpha \beta \gamma \delta}^{0}$ はそれぞれ無ひずみ状態における界面応力および界面弾性係数である.

式(14)の左辺第 1 項について, $x_{3}$ 方向に平面ひずみ状態を想定し, 界面の $\theta$ 方向への曲率を無視し, 变位で整 理すると次式が得られる.

$$
\mathbf{W}_{k}=\left\{\begin{array}{c}
\tau_{11,1}^{k 0}+d_{11 \gamma \delta, 1}^{0} \varepsilon_{\gamma \delta}+d_{11 \gamma \delta}^{0} \varepsilon_{\gamma \delta, 1} \\
\left(\tau_{11}^{k 0}+d_{11 \gamma \delta}^{0} \varepsilon_{\gamma \delta}\right) u_{2,11} v_{2}^{k} \\
\tau_{31,1}^{k 0}+d_{31 \gamma \delta, 1}^{0} \varepsilon_{\gamma \delta}+d_{31 \gamma \delta}^{0} \varepsilon_{\gamma \delta, 1}
\end{array}\right\}=\mathbf{s}_{0 k}+\frac{d \mathbf{S}_{1 k}}{d r} \Omega_{k} \frac{d \mathbf{u}}{d r}+\mathbf{S}_{2 k} \Omega_{k} \frac{d^{2} \mathbf{u}}{d r^{2}}
$$

ここで,

$$
\mathbf{S}_{0 k}=\left\{\begin{array}{c}
\tau_{11,1}^{k 0} \\
0 \\
\tau_{31,1}^{k 0}
\end{array}\right\}, \quad \mathbf{S}_{1 k}=\left[\begin{array}{ccc}
d_{1111}^{k 0} & 0 & d_{1131}^{k 0} \\
0 & 0 & 0 \\
d_{3111}^{k 0} & 0 & d_{3131}^{k 0}
\end{array}\right], \quad \mathbf{S}_{2 k}=\left[\begin{array}{ccc}
d_{1111}^{k 0} & 0 & d_{1131}^{k 0} \\
0 & \tau_{11}^{k 0} v_{2}^{k} & 0 \\
d_{3111}^{k 0} & 0 & d_{3131}^{k 0}
\end{array}\right] \quad, \quad \Omega_{k}=\Omega\left(\theta_{k}\right)
$$

すなわち，界面 $k$ の応力の釣り合い式(14)は以下のようになる.

$$
\mathbf{W}_{k}+\mathbf{T}_{k+1}-\mathbf{T}_{k}=0
$$

ここで， $\mathbf{T}_{k}$ は領域 $k$ の界面の応力である.

自由表面の応力の境界条件は次式のように表すことができる.

$$
\mathbf{W}_{0}+\mathbf{T}_{1}=\mathbf{0} \quad\left(\theta=\alpha_{0}\right), \quad \mathbf{W}_{M}+\mathbf{T}_{M}=\mathbf{0} \quad\left(\theta=\alpha_{M}\right)
$$

界面応力および界面弾性係数を特異点からの距離 $r$ の区分的線形関数であるとする.

$$
\tau_{\alpha \beta}^{k}=\tau_{\alpha \beta i}^{k(a)} \frac{r}{\ell}+\tau_{\alpha \beta i}^{k(b)}, \quad d_{s m n p}^{k}=d_{s m m p i}^{k(a)} \frac{r}{\ell}+d_{s m m p i}^{k(b)} \quad\left(r_{i} \leq r \leq r_{i+1}\right)
$$

式(20)を式(18)に代入し，式を整理すると最終的に次式が得られる. 


$$
\begin{aligned}
& \left\{\left(\mathbf{H}_{10 k}-\frac{\mathbf{H}_{21 k}}{\ell} \lambda\right) \Omega_{k} \mathbf{A}_{k}-\Omega_{k} \mathbf{B}_{k}\right\}\left\langle\hat{p}_{*_{k}}^{1-\lambda}\left(\theta_{k}\right)\right\rangle \mathbf{g}_{k}+\left\{\left(\mathbf{H}_{10 k}-\frac{\mathbf{H}_{21 k}}{\ell} \lambda\right) \Omega_{k} \overline{\mathbf{A}}_{k}-\Omega_{k} \overline{\mathbf{B}}_{k}\right\}\left\langle\overline{\hat{p}}_{*_{k}}^{1-\lambda}\left(\theta_{k}\right)\right\rangle \mathbf{h}_{k} \\
& +\Omega_{k}\left\{\mathbf{B}_{k+1}\left\langle\hat{p}_{* k+1}^{1-\lambda}\left(\theta_{k}\right)\right\rangle \mathbf{g}_{k+1}+\overline{\mathbf{B}}_{k+1}\left\langle\overline{\hat{p}}_{* k+1}^{1-\lambda}\left(\theta_{k}\right)\right\rangle \mathbf{h}_{k+1}\right\}=\mathbf{0}
\end{aligned}
$$

ここで,

$$
\frac{d \mathbf{S}_{1 k}}{d r}=\mathbf{H}_{10 k}=\frac{1}{\ell}\left[\begin{array}{ccc}
d_{1111 i}^{k(a)} & 0 & d_{1131 i}^{k(a)} \\
0 & 0 & 0 \\
d_{3111 i}^{k(a)} & 0 & d_{3131 i}^{k(a)}
\end{array}\right], \quad \frac{d \mathbf{S}_{2 k}}{d r}=\mathbf{H}_{21 k}=\left[\begin{array}{ccc}
d_{a 1111 i}^{k(a)} & 0 & d_{a 1131 i}^{k(a)} \\
0 & \tau_{a 11 i}^{k(a)} v_{2}^{k} & 0 \\
d_{a 1131 i}^{k(a)} & 0 & d_{a 3131 i}^{k(a)}
\end{array}\right]
$$

界面における変位の連続条件から次式が得られる.

$$
\Omega_{k}\left\{\mathbf{A}_{k}\left\langle\hat{p}_{*_{k}}^{1-\lambda}\left(\theta_{k}\right)\right\rangle \mathbf{g}_{k}+\overline{\mathbf{A}}_{k}\left\langle\hat{\bar{p}}_{*_{k}}^{1-\lambda}\left(\theta_{k}\right)\right\rangle \mathbf{h}_{k}\right\}=\Omega_{k}\left\{\mathbf{A}_{k+1}\left\langle\hat{p}_{*_{k+1}}^{1-\lambda}\left(\theta_{k}\right)\right\rangle \mathbf{g}_{k+1}+\overline{\mathbf{A}}_{k+1}\left\langle\hat{\bar{p}}_{*_{k+1}}^{1-\lambda}\left(\theta_{k}\right)\right\rangle \mathbf{h}_{k+1}\right\}
$$

式の変形を容易にするため式(21)と(23)をまとめて，次式のように行列形式で表すことにする.

$$
\begin{aligned}
& \mathbf{G}_{k(k)}\left[\begin{array}{cc}
\left\langle\hat{p}_{* k}^{1-\lambda}\left(\alpha_{k}\right)\right\rangle & \mathbf{0} \\
\mathbf{0} & \left\langle\hat{\hat{p}}_{* k}^{1-\lambda}\left(\alpha_{k}\right)\right\rangle
\end{array}\right]\left\{\begin{array}{c}
\mathbf{g}_{k} \\
\mathbf{h}_{k}
\end{array}\right\} \\
& =\Omega_{k}\left[\begin{array}{cc}
\mathbf{A}_{k+1} & \overline{\mathbf{A}}_{k+1} \\
\mathbf{B}_{k+1} & \overline{\mathbf{B}}_{k+1}
\end{array}\right]\left[\begin{array}{cc}
\left\langle\hat{p}_{* k+1}^{1-\lambda}\left(\alpha_{k}\right)\right\rangle & \mathbf{0} \\
\mathbf{0} & \left\langle\overline{\hat{p}}_{* k+1}^{1-\lambda}\left(\alpha_{k}\right)\right\rangle
\end{array}\right]\left\{\begin{array}{c}
\mathbf{g}_{k+1} \\
\mathbf{h}_{k+1}
\end{array}\right\}=\left\{\begin{array}{c}
\mathbf{p}_{k} \\
\mathbf{q}_{k}
\end{array}\right\}
\end{aligned}
$$

ここで， $\mathbf{G}_{k(s)}$ は次式で与えられる．

$$
\mathbf{G}_{k(s)}=\Omega_{k}\left[\begin{array}{cc}
\mathbf{A}_{k} & \overline{\mathbf{A}}_{k} \\
\mathbf{B}_{k} & \overline{\mathbf{B}}_{k}
\end{array}\right]-\left(\mathbf{H}_{10 s}-\frac{\mathbf{H}_{21 s}}{\ell} \lambda\right) \Omega_{k}\left[\begin{array}{cc}
0 & 0 \\
\mathbf{A}_{k} & \overline{\mathbf{A}}_{k}
\end{array}\right]
$$

さらに，式(24)のように界面 $k$ の境界条件から得られる関係式をべクトル $\left\{\boldsymbol{p}_{\mathrm{k}}, \boldsymbol{q}_{\mathrm{k}}\right\}^{\mathrm{T}}$ で表す.

これまでの式の導出は，既報（Koguchi and Suzuki, 2014）で詳細に説明してあるが，最終的な特性方程式は 2 相体に限定されている. 本論文でより一般的な式を示す. 寸なわち, 本解析で使用する $M$ 相接合体の特異性の才 一ダを求める固有方程式は以下のように一般化することにより求めることができる. まず, 係数べクトル $\left\{\boldsymbol{p}_{\mathrm{k}}, \boldsymbol{q}_{\mathrm{k}}\right\}^{\mathrm{T}}$ と $\left\{\boldsymbol{p}_{\mathrm{k}+1}, \boldsymbol{q}_{\mathrm{k}+1}\right\}^{\mathrm{T}}$ には次の関係がある.

$$
\left\{\begin{array}{c}
\mathbf{p}_{k} \\
\mathbf{q}_{k}
\end{array}\right\}=\Omega_{k}\left[\begin{array}{cc}
\mathbf{A}_{k+1} & \overline{\mathbf{A}}_{k+1} \\
\mathbf{B}_{k+1} & \overline{\mathbf{B}}_{k+1}
\end{array}\right]\left[\begin{array}{cc}
\left\langle\hat{p}_{*_{k+1}}^{1-\lambda}\left(\alpha_{k}\right) \hat{p}_{* k+1}^{\lambda-1}\left(\alpha_{k+1}\right)\right\rangle & \mathbf{0} \\
\mathbf{0} & \left\langle\overline{\hat{p}}_{*_{k+1}}^{1-\lambda}\left(\alpha_{k}\right) \overline{\hat{p}}_{*_{k+1}}^{\lambda-1}\left(\alpha_{k+1}\right)\right\rangle
\end{array}\right] \mathbf{G}_{k(s)}^{-1}\left\{\begin{array}{l}
\mathbf{p}_{k+1} \\
\mathbf{q}_{k+1}
\end{array}\right\}
$$

式(26)の右辺の関係式を次式で置き換える.

$$
\breve{\mathbf{N}}_{j}^{1-\lambda}\left(\alpha_{j-1}, \alpha_{j}\right)=\Omega_{j-1}\left[\begin{array}{cc}
\mathbf{A}_{j} & \overline{\mathbf{A}}_{j} \\
\mathbf{B}_{j} & \overline{\mathbf{B}}_{j}
\end{array}\right]\left[\begin{array}{cc}
\left\langle\hat{p}_{*_{k+1}}^{1-\lambda}\left(\alpha_{k}\right) \hat{p}_{*_{k+1}}^{\lambda-1}\left(\alpha_{k+1}\right)\right\rangle & \mathbf{0} \\
\mathbf{0} & \left\langle\overline{\hat{p}}_{*_{k+1}}^{1-\lambda}\left(\alpha_{k}\right) \overline{\hat{p}}_{*_{k+1}}^{\lambda-1}\left(\alpha_{k+1}\right)\right\rangle
\end{array}\right] \mathbf{G}_{j(j)}^{-1}
$$

式(26)から $\left\{\boldsymbol{p}_{\mathrm{M}-1}, \boldsymbol{q}_{\mathrm{M}-1}\right\}^{\mathrm{T}}$ を求め, 整理すると,

$$
\left[\begin{array}{ll}
\mathbf{0} & \mathbf{I}
\end{array}\right] \prod_{j=1}^{M} \breve{\mathbf{N}}_{j}^{1-\lambda}\left(\alpha_{j-1}, \alpha_{j}\right)\left\{\begin{array}{l}
\mathbf{p}^{*} \\
\mathbf{q}^{*}
\end{array}\right\}=0
$$

という関係が導かれる。ここで,

$$
\breve{\mathbf{E}}=\left[\begin{array}{cc}
\breve{\mathbf{E}}_{1} & \breve{\mathbf{E}}_{2} \\
\breve{\mathbf{E}}_{3} & \breve{\mathbf{E}}_{4}
\end{array}\right]=\prod_{j=1}^{M} \breve{\mathbf{N}}_{j}^{1-\lambda}\left(\alpha_{j-1}, \alpha_{j}\right)
$$


と置けば，未知ベクトル $\left\{\boldsymbol{p}^{*}, \boldsymbol{q}^{*}\right\}^{\mathrm{T}}$ について

$$
\breve{\mathbf{E}}_{3} \mathbf{p}^{*}=\mathbf{0}, \mathbf{q}^{*}=\mathbf{0}
$$

となるため,

$$
\left|\breve{\mathbf{E}}_{3}\right|=0
$$

を解けば，固有值 $\lambda$ が求められる.

\section{$2 \cdot 3$ 角度関数}

変位, 応力に対する角度関数をそれぞれ $\mathbf{g}_{k}(\theta), \mathbf{f}_{k}(\theta)$ とする. 式(27)で示した $\breve{\mathbf{N}}_{j}^{1-\lambda}$ を用いて, 角度関数は次式 でのように与えられる。

$$
\left\{\begin{array}{c}
\mathbf{g}_{k}(\theta) \\
\mathbf{f}_{k}(\theta)
\end{array}\right\}=\breve{\mathbf{N}}_{k}^{1-\lambda}\left(\theta, \alpha_{k}\right) \prod_{j=k}^{M} \breve{\mathbf{N}}_{j+1}^{1-\lambda}\left(\alpha_{j}, \alpha_{j+1}\right)\left\{\begin{array}{l}
\mathbf{p}^{*} \\
\mathbf{q}^{*}
\end{array}\right\}
$$

なお, 領域 $k$ の変位と応力関数は $\left\{\mathbf{u}_{k}, \phi_{k}\right\}^{T}=r^{1-\lambda}\left\{\mathbf{g}_{k}, \mathbf{f}_{k}\right\}^{T}$ で与えられる.

本研究では，以上の式に対する mathematica のプログラムを作成し，特異性のオーダ，角度関数を求めた.

\section{3 領域くさび形接合体の界面特性}

\section{$3 \cdot 1$ 解析モデルと解析条件}

はじめに, 外力を負荷しないで原子の安定位置を求め, 界面特性を調べる. そのために分子静力学解析を行う. 分子静力学解析には, 半経験的ポテンシャルである GEAM (Generalized Embedded Atom Method) (Zhou et al., 2001) を用いる.また，界面特性の定義については既報 (Koguchi and Suzuki, 2014)を参照されたい. まず分子静力学解析 に用いるモデルを図 3 に示す. モデル半径は $7 \mathrm{~nm}$ とし， $x_{3}$ 方向に周期境界条件を適用している. 材料は，1:ニッ ケル $(\mathrm{Ni}), 2$ :金 $(\mathrm{Au}), 3$ :銅 $(\mathrm{Cu})$ とし，界面を作る結晶方位および材料の開き角 $\omega$ は表 1 のように 3 種類の モデルを作成し, 解析する. 界面は整合界面とし, 格子定数は全材料の平均值 $a_{a v e}=0.3838 \mathrm{~nm}$ とした. ちなみに, 各材料の格子定数は $a_{\mathrm{Ni}}=0.3520 \mathrm{~nm}, a_{\mathrm{Au}}=0.4080 \mathrm{~nm}, a_{\mathrm{Cu}}=0.3614 \mathrm{~nm}$ である.

1 ステップあたりの時間は $5 \mathrm{fs}$ である. $0 \mathrm{~K}$ から計算を始め, 500 ステップ後に $0.5 \mathrm{~K}$ まで上昇させ， 6,500 ステ ップまで $0.5 \mathrm{~K}$ を維持する. その後 9,000 ステップ後までに $0 \mathrm{~K}$ 一温度を下げる. 9,000 ステップ以降は $0 \mathrm{~K}$ を保ち 原子の位置を安定させ，10,000 ステップまで計算を行う.

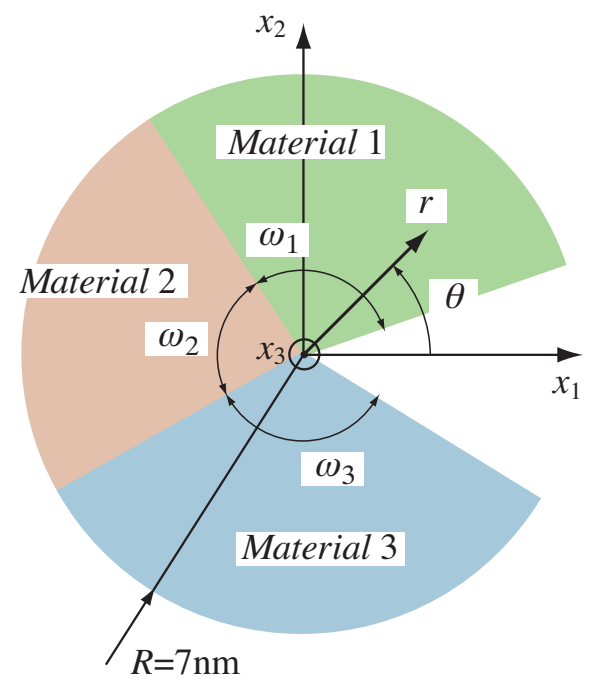

Fig.3 Three-wedge model for analysis, radius of model is $7 \mathrm{~nm}$. The periodic condition is applied in the $x_{3}$ direction. The wedge angles are $\omega_{1}$ for material $1, \omega_{2}$ for material 2 and $\omega_{3}$ for material 3 . 
Table 1 Joined planes and wedge angle.

\begin{tabular}{|c|c|c|c|c|c|}
\hline \multirow{2}{*}{ No. } & \multicolumn{2}{|c|}{ 接合面 } & \multicolumn{3}{|c|}{ 開き角 $\omega, \operatorname{deg}$} \\
\hline & $\mathrm{Ni}-\mathrm{Au}$ & $\mathrm{Au}-\mathrm{Cu}$ & $\mathrm{Ni}$ & $\mathrm{Au}$ & $\mathrm{Cu}$ \\
\hline 1 & \multirow{3}{*}{ (110) } & \multirow{3}{*}{ (110) } & 90 & \multirow{3}{*}{90} & 90 \\
\hline 2 & & & 110 & & 110 \\
\hline 3 & & & 120 & & 120 \\
\hline
\end{tabular}

\section{2 界面特性を考慮しない固有值解析の結果}

表 2 に各材料の弾性係数を示す.この值を用いて, 界面特性を考慮しない場合の特異性の才一ダ $\lambda$ を求めると, 表 3 のように得ることができる. 次に, それぞれの固有值に対する角度関数 $f_{\theta \theta}(\theta)$ を求めた結果を図 4 に示す. な お，これらの図で $\lambda_{k}$ に対する角度関数を $f^{k}$ としてプロットしている. 表面でゼロ, 界面で連続な分布となる関数 が得られたが， $\lambda_{1}$ に対する角度関数は $f^{1}(\theta)=0$ となった.

Table 2 Material properties.

\begin{tabular}{|c||c|c|c|}
\hline Material & $\mathrm{C}_{11}, \mathrm{C}_{22}, \mathrm{C}_{33}$ & $\mathrm{C}_{12}, \mathrm{C}_{13}, \mathrm{C}_{23}$ & $\mathrm{C}_{44}, \mathrm{C}_{55}, \mathrm{C}_{66}$ \\
\hline \hline $\mathrm{Ni}$ & 242.71 & 144.98 & 122.54 \\
\hline $\mathrm{Au}$ & 186.08 & 157.11 & 42.01 \\
\hline $\mathrm{Cu}$ & 169.29 & 121.97 & 75.61 \\
\hline
\end{tabular}

unit: $\mathrm{GPa}$

Table 3 Eigenvalues without interface properties.

\begin{tabular}{|c||c|c|c|}
\hline Model No. & $\lambda_{1}$ & $\lambda_{2}$ & $\lambda_{3}$ \\
\hline \hline 1 & 0.5075 & 0.5224 & 0.6951 \\
\hline 2 & 0.4620 & 0.4664 & 0.5109 \\
\hline 3 & 0.4372 & 0.4503 & 0.4766 \\
\hline
\end{tabular}

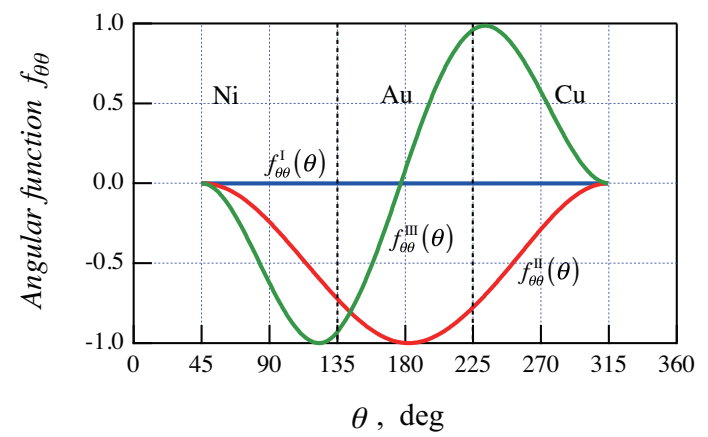

(a) Model 1

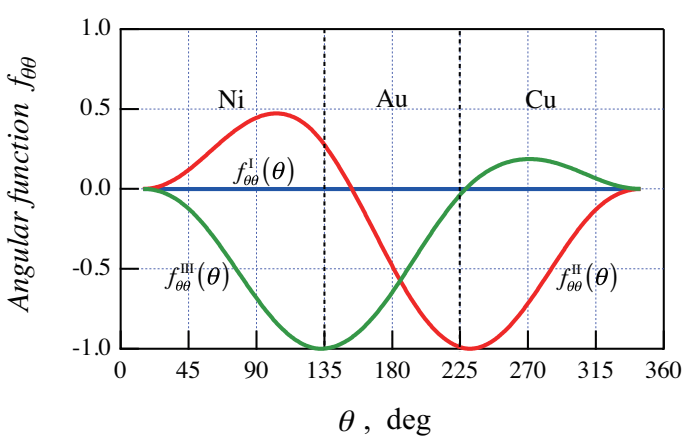

(c) Model 3

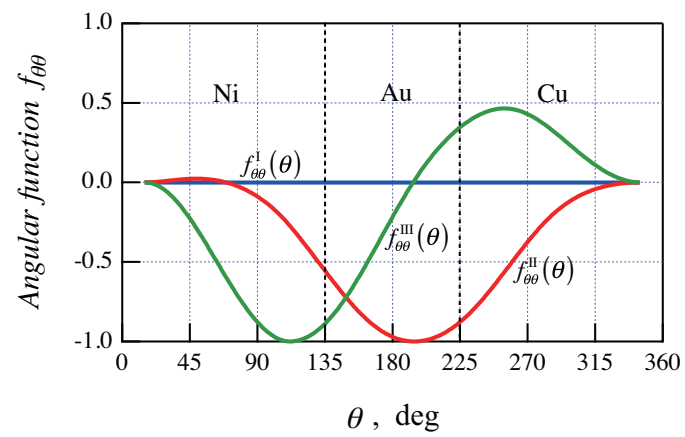

(b) Model 2

Fig.4 Angular function, $f_{\theta \theta}$, without interface properties, (a) Model $1\left(\omega_{1}=\omega_{2}=\omega_{3}=90^{\circ}\right)$, (b) Model $2\left(\omega_{1}=\omega_{3}=110^{\circ}, \omega_{2}=90^{\circ}\right)$, (c) Model $3\left(\omega_{1}=\omega_{3}=120^{\circ}, \omega_{2}=90^{\circ}\right)$. 


\section{$3 \cdot 3$ 界面特性}

界面近傍の原子に対し原子界面応力, 界面弾性係数を求めた。 それらを式(33)でフィッティングし，角部から の距離 $r / \ell$ の関数として表す. 表面近傍では界面応力の影響があるため $r / \ell \leq 6$ の範囲で近似した.

$$
g(r / \ell)=C_{1} \mathrm{e}^{C_{2}(r / \ell)} \cos \left(C_{3} r / \ell\right)+C_{4}(r / \ell)^{C_{5}}+C_{6}
$$

ここで, $\ell=1 \mathrm{~nm}$ とする.

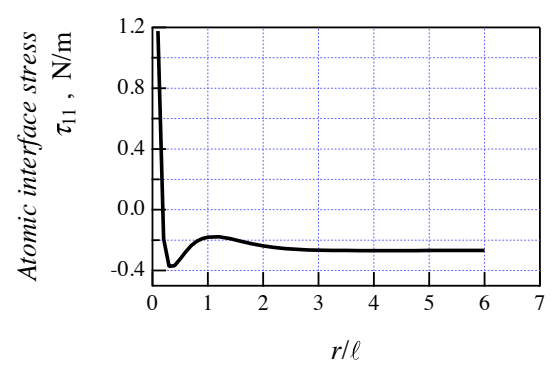

(a) Interface stress $\tau_{11}$

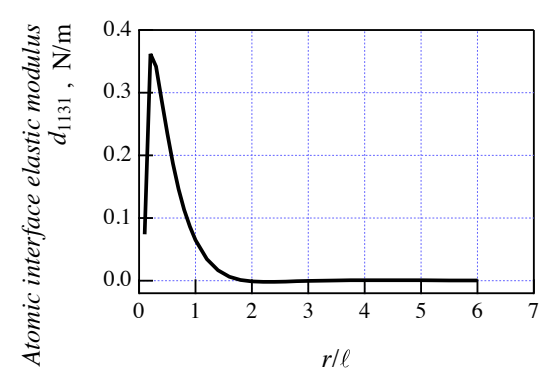

(c) Interface elastic moduli $d_{1131}$

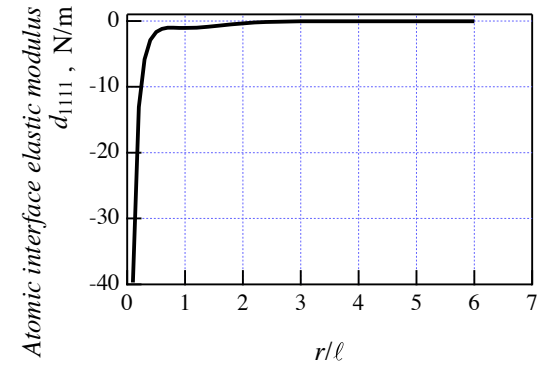

(b) Interface elastic moduli $d_{1111}$

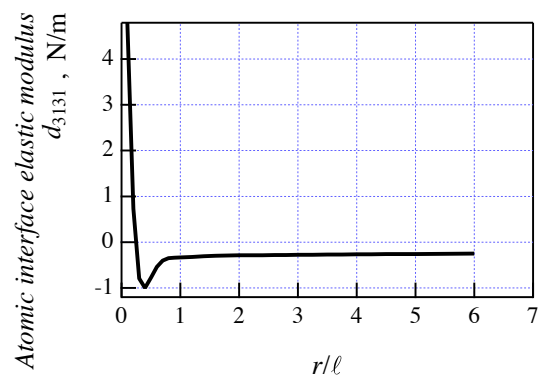

(d) Interface elastic moduli $d_{3131}$

Fig. 5 Variations of interface properties between $\mathrm{Ni}$ and $\mathrm{Au}$ in model 1 with the distance from the origin,

(a) Interface stress $\tau_{11}$, (b) Interface elastic moduli $d_{1111}$, (c) Interface elastic moduli $d_{1131}$, (d) Interface elastic moduli $d_{3131}$.

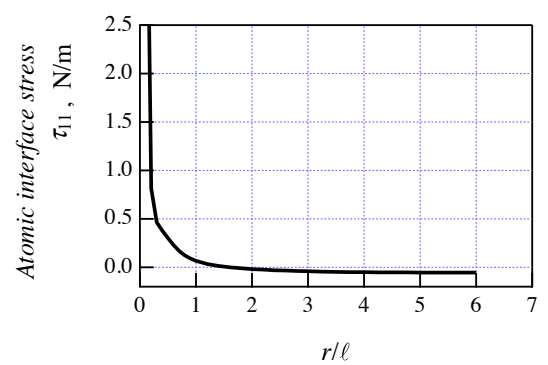

(a) Interface stress $\tau_{11}$

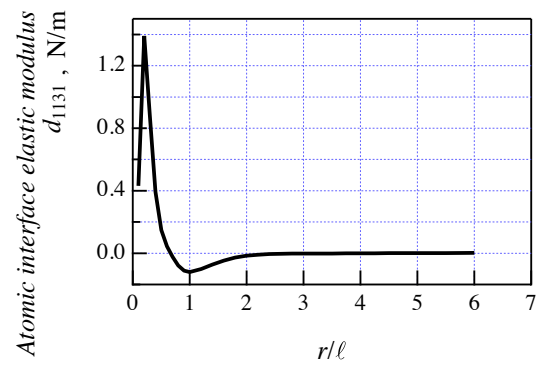

(c) Interface elastic moduli $d_{1131}$

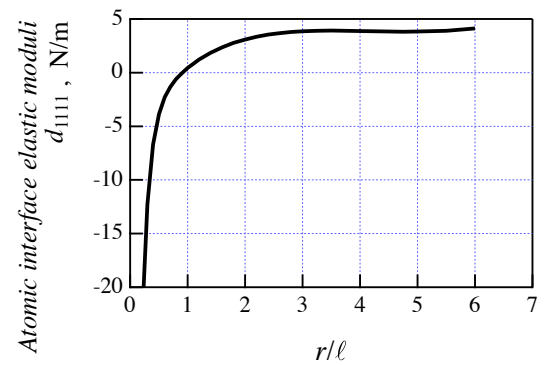

(b) Interface elastic moduli $d_{1111}$

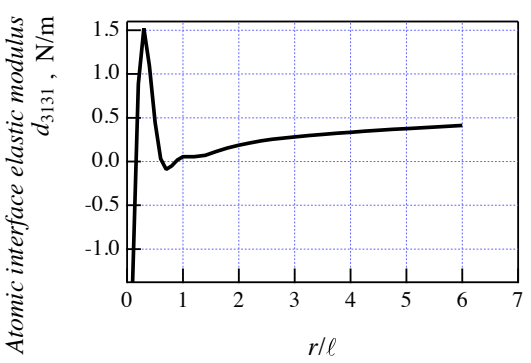

(d) Interface elastic moduli $d_{3131}$

Fig. 6 Variations of interface properties between $\mathrm{Au}$ and $\mathrm{Cu}$ in model 1 with the distance from the origin,

(a) Interface stress $\tau_{11}$, (b) Interface elastic moduli $d_{1111}$, (c) Interface elastic moduli $d_{1131}$, (d) Interface elastic moduli $d_{3131}$. 
一例として図 5 と図 6 にモデル 1 の界面特性を示す. 図中の実線は式(33)でフィッティングした界面特性の界 面端からの距離に対寸る関係を示している. どのモデルにおいても，角部近傍 $r / \ell<1.0$ で界面特性が大きく変化 し，角部から離れるにともない一定の值に収束していることがわかる.

\section{$3 \cdot 4$ 界面特性を考慮した固有値解析}

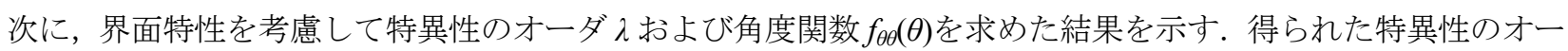
ダ $\lambda$ を図 7 に示す. 破線は界面特性を考慮しない場合の特異性のオーダの值（表 3）を示す. 図中の実線は $r$ に 対し式(31)を解いて特異性のオーダ $\lambda$ を求め, 界面特性と同様に式(33)で $r$ の関数として表した結果である. 界面 特性が角部からの距離の関数のため, 特異性のオーダ $\lambda$ も同様に $r$ の関数として表される. 界面特性の影響で $r<$ $1 \mathrm{~nm}$ の範囲で特異性のオーダの值は大きく変化する. 角部から離れると $\lambda^{\mathrm{II}}, \lambda^{\mathrm{III}}$ は界面特性を考慮しない場合と

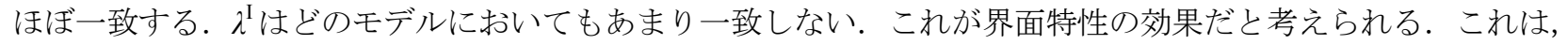
以下のことからも言うことができる.

次に, 図 8 に界面特性を考慮した特異性のオーダから算出した角度関数 $f_{\theta \theta}$ を示寸. 界面特性を考慮したことで, $\lambda_{\mathrm{I}}$ に対して0でない角度関数が得られている. また, 界面において值は連続しているが, 滑らかではない分布が 得られたことも注目される。

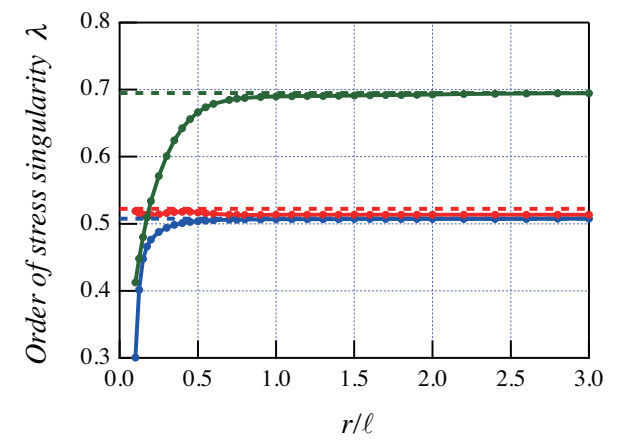

(a) Model 1

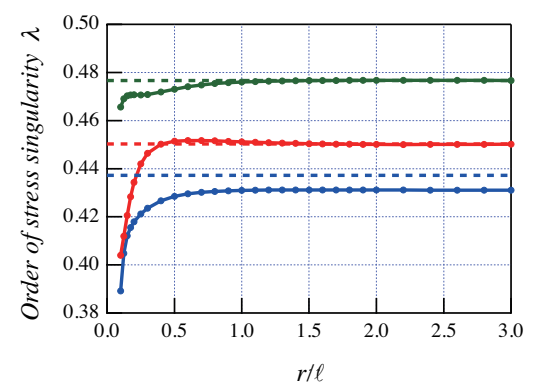

(c) Model 3

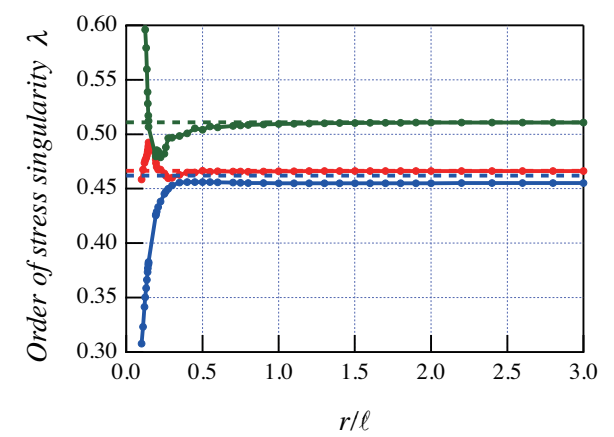

(b) Model 2

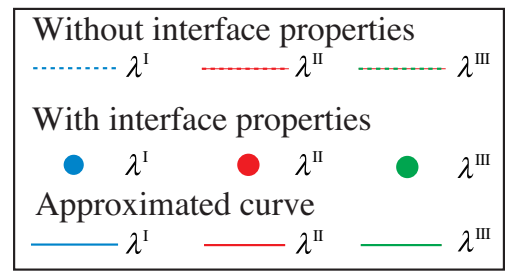

Fig.7 Comparison of values yielding the stress singularity obtained from the theory with the interface properties and without them. Solid lines indicate the results with interface properties and demonstrate the dependence of distance from the origin. The values vary largely near the stress singular point. Dashed lines indicate the results without interface properties.

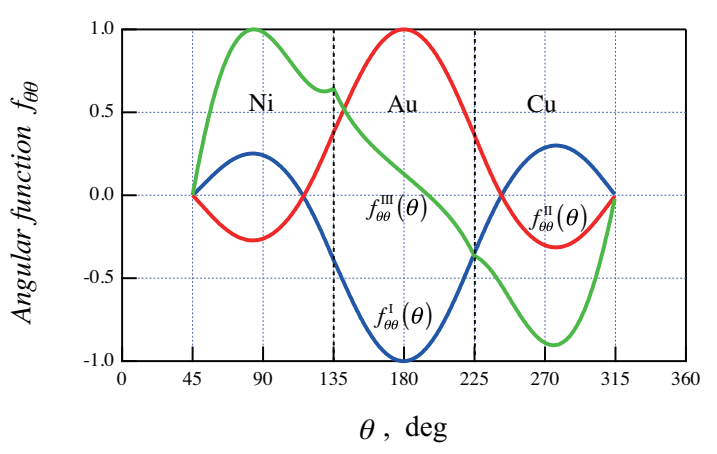

(a) Model 1

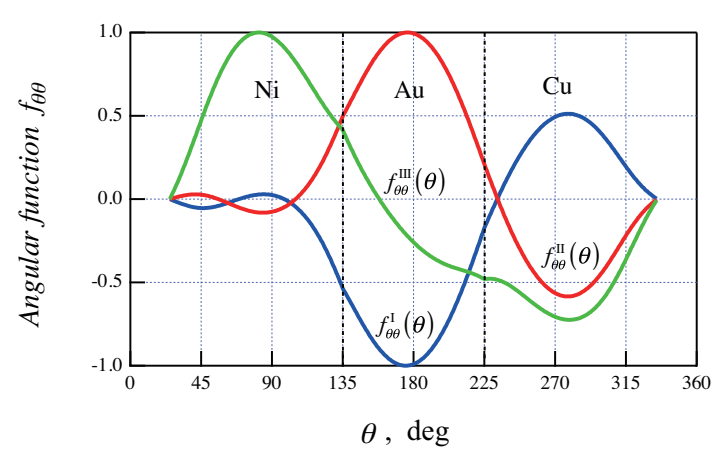

(b) Model 2 


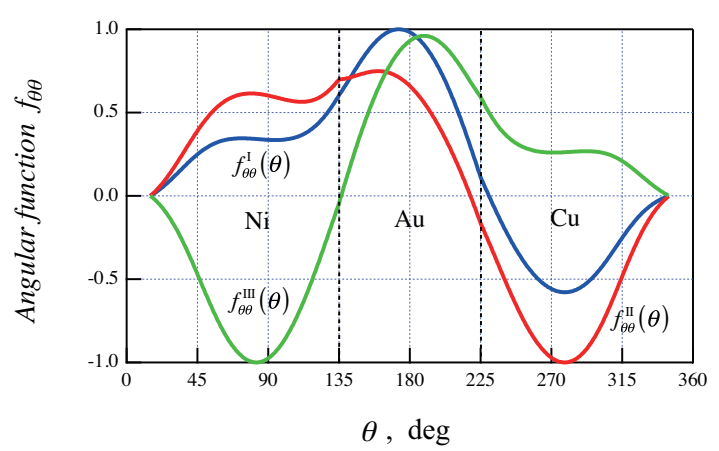

(c) Model 3

Fig.8 Angular functions for the values of stress singularity with interface properties. In a comparison with Fig. 4, the angular functions for all values yielding the stress singularity vary against the angle $\theta$.

\section{$3 \cdot 5$ 外カの作用する解析モデルと解析結果}

次に図 3 のモデルに対し, 図 9 に示すように表面近傍原子の外表面の法線方向に外力(100MPa)を与えた場 合の結果を示寸. 図 10 に $x_{1}-x_{2}$ 面における応力 $\sigma_{\theta \theta}$ の分布を示す. 図 10 (a)-(c)において開口部の大きさの違 いによる応力分布を比較すると, 開口部が最も大きいモデル 1 では角部近傍で応力が高くなっている. モデ ル 2, 3 と開口部が小さくなるにつれて材料 2 の $\mathrm{Au}$ 領域全体に応力が分布している. これらの界面の結晶 方位は(110)面である. 面心立方構造(face-centered cubic: fcc)におけるす心゙り面は\{111\}面であり，そのすべり 方向は[110]である. そのため, 寸べりやすい(110)面接合の界面に偏った忘力分布となったと考えられる. 以上のことから，材料の組み合わせよりも接合面を作る結晶方位の影響が大きいということがわかった。

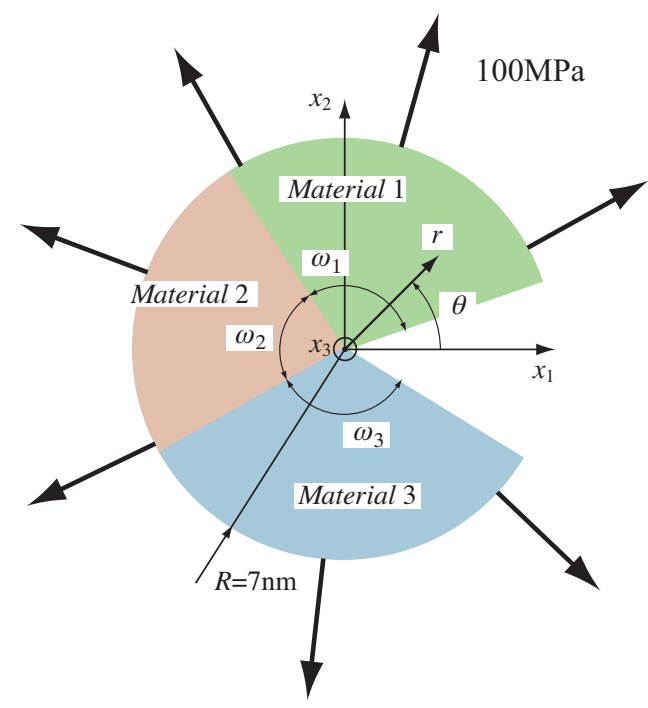

Fig.9 Wedge model for analysis under an external loading of 100MPa.

図 11 に $r=2 \mathrm{~nm}$ 近傍における応力 $\sigma_{\theta \theta}$ の $\theta$ に対する分布を示す.いずれも応力の最大值は約 $120 \mathrm{MPa}$ 程度となり, 外力 $(100 \mathrm{MPa})$ 相当の応力が生じている. それぞれの材料内では応力分布は連続しているが，界面近傍では材 料定数の違いにより不連続な分布となっている. また, 材料 2 の $\mathrm{Au}$ 領域の忘力分布を見ると, $\theta=180^{\circ}$ よりも $\mathrm{Ni}$ 側に寄った位置にピークがあり, $\theta=135^{\circ}$ 付近で最大となっている. 各領域の材料特性のうち $\mathrm{C}_{11}$ の大きさを比較 すると, $\mathrm{Ni}>\mathrm{Au}>\mathrm{Cu}$ の順に大きい. また, $\mathrm{Ni}-\mathrm{Au}$ の組み合わせの方が $\mathrm{Au}-\mathrm{Cu}$ よりも材料の特性が大きく異なって いる.この材料特性の違いが大きい界面の方に応力の最大值が寄っていることがわかる. 


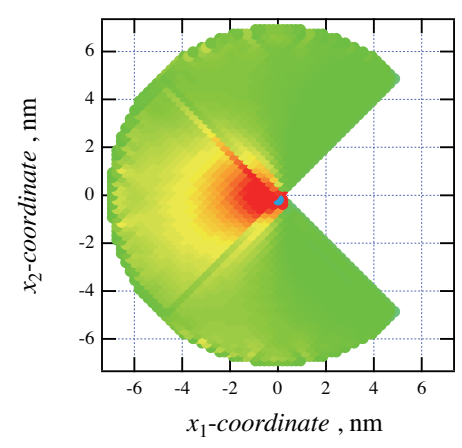

(a) Model 1

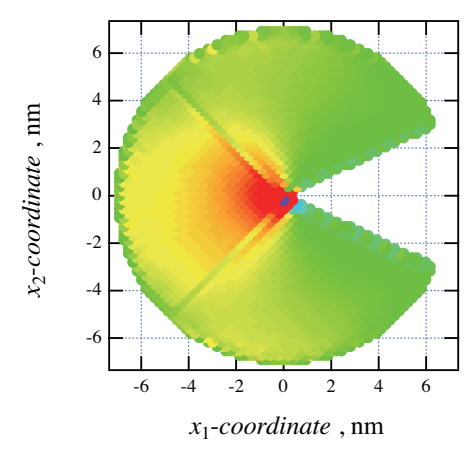

(b) Model 2

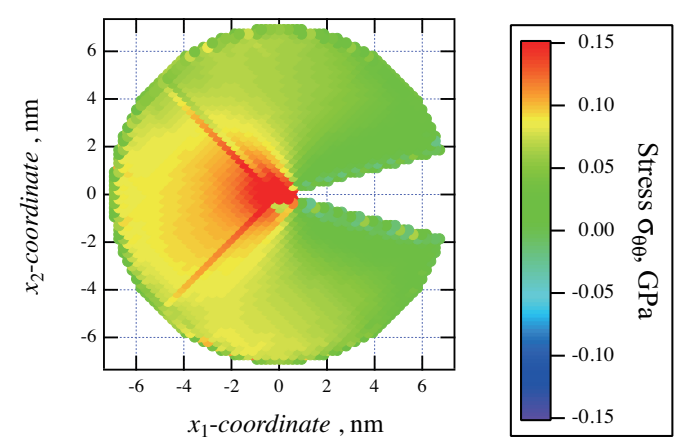

(c) Model 3

Fig.10 Maps of stress $\sigma_{\theta \theta}$ on $x_{3}=0$, open wedge angle is $90^{\circ}$ in Model $1,50^{\circ}$ in Model 2 and $30^{\circ}$ in Model 3. Stress $\sigma_{\theta \theta}$ in Model 1 concentrates at the wedge tip than that in Models 2 and 3. As reducing the open wedge angle, the stress, $\sigma_{\theta \theta}$, in Au region spreads widely.

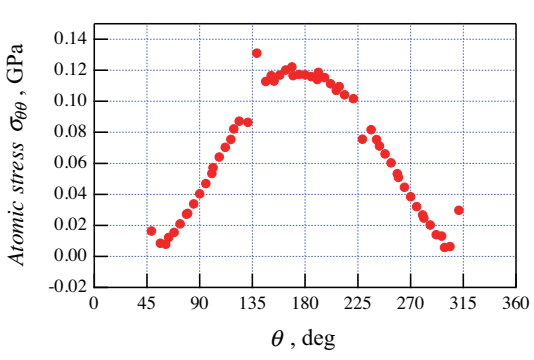

(a) Model 1

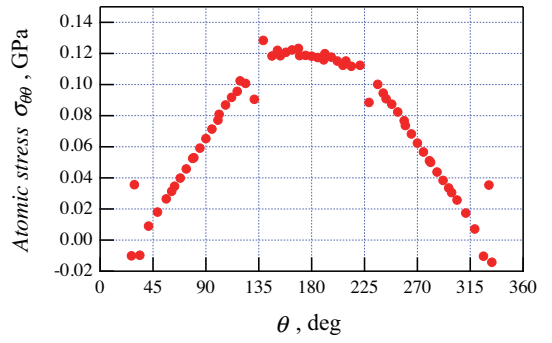

(b) Model 2

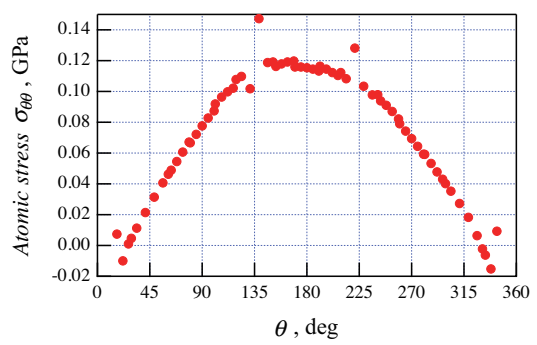

(c) Model 3

Fig.11 Stress $\sigma_{\theta \theta}$ distribution on $r \fallingdotseq 2 \mathrm{~nm}$, the distribution of $\sigma_{\theta \theta}$ widens with the decrease of open angle and the maximum stress of $\sigma_{\theta \theta}$ shifts slightly to the Ni region (Material 1).

\section{$3 \cdot 6$ 分子静力学解析と理論の比較 ( $\theta$ に対する応力分布)}

ここでは, 前節で示した分子静力学から得られた $\theta$ に対する応力分布と固有值解析から得られた角度関数の比 較を行う. 角部近傍の特異応力場は特異性のオーダ $\lambda$ と角度関数 $f_{i j}(\theta)$ を用いて式(1)で与えられる.ここで, 一定 の $r$ において $r^{-\lambda_{k}}=$ const. となる. また，前節で示したように特異性のオーダ $\lambda$ は 3 つ存在する. そこで，図 11 の応力分布を次式で近似し，最小二乗法で定数 $K_{k}^{M}$ を決定する.

$$
\sigma_{\theta \theta}^{M}=K_{1}^{M} f_{\theta \theta}^{1 M}+K_{2}^{M} f_{\theta \theta}^{2 M}+K_{3}^{M} f_{\theta \theta}^{3 M}
$$

決定された定数の值を表 4 に示す. また, 分子静力学解析の結果と式(34)で求めた応力分布を図 12 に示す. 図中 の赤丸が分子静力学法による結果，青の破線は界面特性を考慮しない場合，緑の実線は界面特性を考慮した場合 の結果である. $\mathrm{Ni}, \mathrm{Cu}$ の領域内では界面特性を考慮しない場合および考慮した場合とも分子静力学の結果とよく

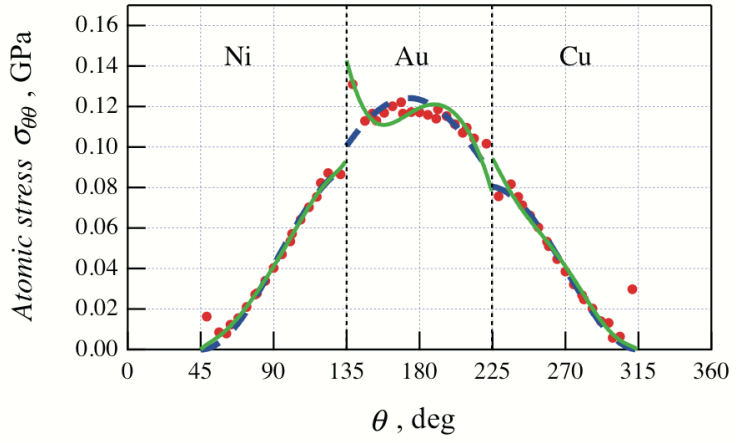

(a) Model 1

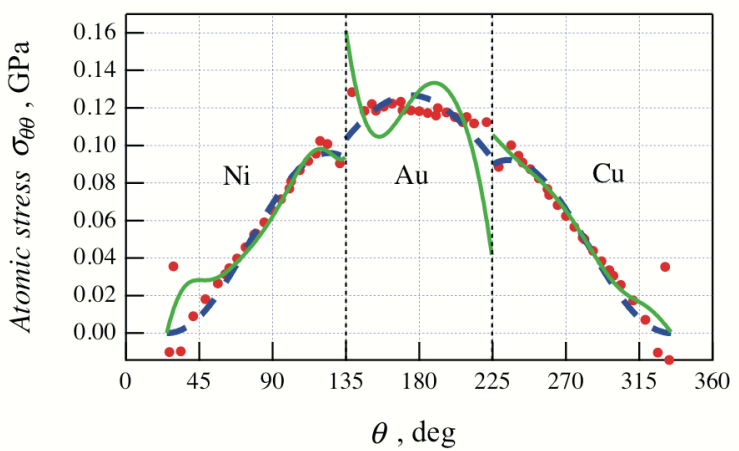

(b) Model 2 

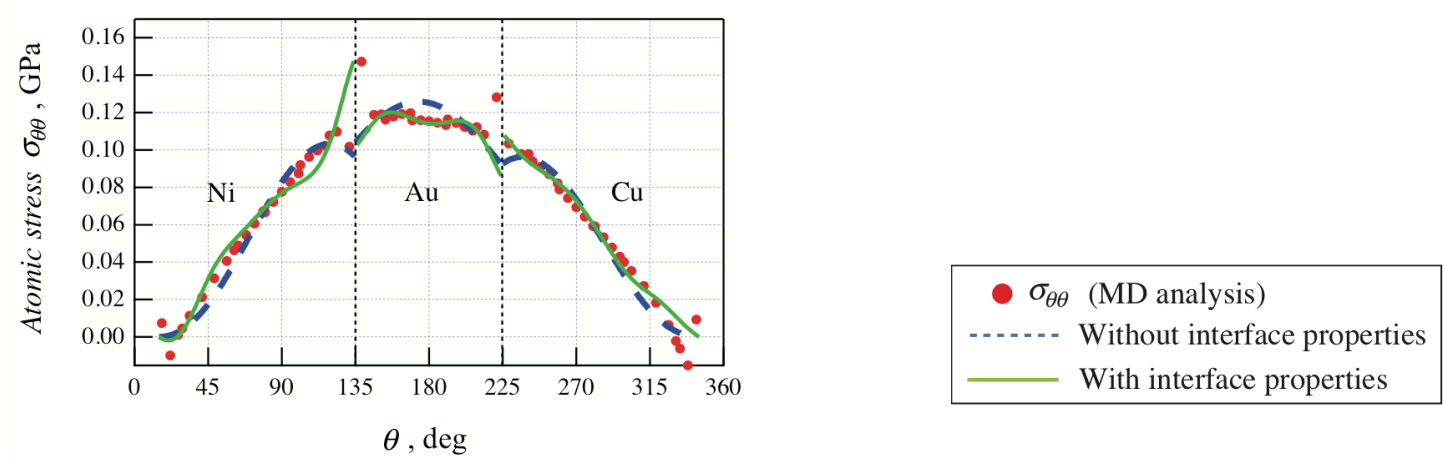

(c) Model 3

Fig.12 Comparison of stress $\sigma_{\theta \theta}$ distributions obtained from the MS method, the theories with interface properties and without them on $r=2 \mathrm{~nm}$. Green solid line and red dashed line indicate the distribution calculated using Eq.(48) and the values in Table 4. The present theory can express the jump at the interface in the MS result.

一致している. $\mathrm{Au}$ 領域は，モデル 1 から 3 のような凸状の分布の場合界面特性を考慮しない場合でもよく一致し ている. 界面特性を考慮した場合, モデル 1,3 は界面特性を考慮しない場合と比較してよく一致している.また， 界面特性を考慮した方が分子静力学で得られた界面付近の応力不連続をよく表している，しかし，モデル 2 の $\mathrm{Au}$ 領域では，界面特性を考慮した場合，分子静力学の応力分布より応力不連続が過大になった。このことについて は今後検討する必要があるが，分子静力学などの非連続系の計算では，接合界面間角度の組み合わせにより界面 ですべりが生じる可能性がある。これにより応力分布が滑らかになることが考えられる.

Table 4 The values for intensity of stress singularity determined using a least square method.

\begin{tabular}{|c||c|c|c||c|c|c|}
\hline \multicolumn{1}{|c||}{ model No. } & \multicolumn{3}{c||}{ Ni-Au interface } & \multicolumn{3}{c|}{ Au-Cu interface } \\
\cline { 2 - 7 } & $K_{1}$ & $K_{2}$ & $K_{3}$ & $K_{1}$ & $K_{2}$ & $K_{3}$ \\
\hline \hline 1 & 0.35 & -0.13 & -0.07 & -1.4 & 1.6 & -0.07 \\
\hline 2 & -1.13 & 0.97 & 0.34 & -2.58 & 2.69 & 0.05 \\
\hline 3 & -1.14 & 1.46 & -0.16 & -2.98 & 4.16 & -1.03 \\
\hline
\end{tabular}

本研究で考案された解析方法は, 界面を構成する材料の力学的特性が場所により変化するような傾斜機能性材 料の接合端における応力解析などにも拡張できると考えられる.

\section{4. 結言}

ニッケル，金，銅からなるくさび型の 3 相接合体の界面端の特異応力場について分子静力学解析および異方性 弾性論を用いて調べた。 得られた結果を以下にまとめる.

1) 界面特性を考慮した $M$ 相接合体の接合界面端の特異応力場の特異性のオーダを求めるため一般化した特性方 程式を求め，特異応力場の角度関数に対する一般式を導出した.

2) 3 相接合体について，分子静力学により界面特性を特異点からの距離に対して求めた。求めた界面特性を 3 相接合体の特性方程式に適用し固有值解析を行い，特異性のオーダと角度関数を求めた. 界面特性はくさび 形状の先端からの距離 $r<1 \mathrm{~nm}$ の範囲で大きく変化し，これは先端に近づくに伴い界面同士が接近し，界面 の相互干渉および界面応力による原子配列の変更が起こるためと考えられる.

3) 分子静力学解析で得られた $\theta$ 方向の応力 $\sigma_{\theta \theta}$ の分布について, 3 相接合体の材料 2 の開き角を $90^{\circ}$ に固定し, 材 料 1 と 3 の開き角の大きさを $120^{\circ}, 110^{\circ}, 90^{\circ}$ と変えると材料 2 内の応力が拡がりを持つ分布から特異点に 集中する分布に変わっていく，さらに形状が上下対称でも力学的特性の非対称性により，応力分布も非対称 
性になる. このように 3 相接合体の材料 1 と 3 の領域の大きさが, 界面に挟まれた領域の応力分布に界面を 通して強く影響していることがわかった。

4) 分子静力学で得られた応力 $\sigma_{\theta \theta}$ の分布は, 各材料内で連続しているが, 界面では不連続な分布となる. この応 力分布は本研究で導出した界面特性を考慮した理論式から得られた応力分布と概ね一致した. しかし, 界面 特性を考慮した場合, 界面間角度に依っては分子静力学の応力分布より応力不連続が過大になることがあっ た.このことについては今後検討する必要があるが, 分子静力学などの非連続系の計算では, 接合界面間角 度の組み合わせにより界面ですべりが生じ, 応力分布が変わる可能性がある.

\section{謝 辞}

本研究は, 科学研究補助金（基盤研究（B）（一般）（26289003）の援助を受けて行われたものであり, 関係各 位には心から謝意を表する.

\section{文献}

Bogy, D.B., Two edge-bonded elastic wedges of different materials and wedge angles under surface tractions, Transactions of the ASME, Journal of Applied Mechanics, Vol. 38, No.2 (1971), pp.377-386.

Dempsey, J.P. and Sinclair, G.B., On the stress singularities in the plane elasticity of the composite wedge, Journal of Elasticity, Vol.9, No.4 (1979), pp.373-391.

Gurtin, M.E. and Murdoch, A.I., A continuum theory of elastic material surfaces, Archive for Rational Mechanics and Analysis, Vol. 57, No.4 (1975), pp.291-323.

Hanbucken, M., Muller, P. and Wehrspohn, R. B., Mechanical Stress on the Nanoscale, Wiley-VCHVerlag \& Co. KGaA, (2011), Germany.

堀池弘一, 池田徹, 松本龍介, 宮崎則幸, 分子静力学法を用いた異種結晶材料接合か溝の特異応力場解析と混合 モード破壊じん性值の評価, 日本材料学会, Vol.59, No.12 (2010), pp.908-915.

Hwu, C., Omiya, M. and Kishimoto, K., A key matrix N for the stress singularity of the anisotropic elastic composite wedges. JSME International Journal Series A, Vol. 46, No.1 (2003), pp.40-50.

Ibach, H., The role of surface stress in reconstruction, epitaxial growth and stabilization of mesoscopic structures, Surface Science Reports, Vol.29 (1997), pp.195-263.

Izumi, S., Hara, S., Kumagami, T. and Sakai, S., A method for calculating surface stress and surface elastic constants by molecular dynamics: application to the surface of crystal and amorphous silicon, Thin Solid Film, Vol. 467, No.1-2 (2004), pp.253-260.

Kim, C. I., Schiavone, P. and Ru, C. -Q., The effects of surface elasticity on an elastic solid with mode-III crack: Complete solution, Journal of Applied Mechanics, Vol.77, No.2 (2010a), DOI: 10.1115/1.3177000.

Kim, C. I., Ru, C-Q. and Schiavone, P., Analysis of plane-strain crack problems (mode-I \& mode-II) in the presence of surface elasticity, Journal of Elasticity, Vol. 104, No.1 (2010b), 397-420, DOI:10.1007/s10659-010-9287-0.

Kim, C. I., Schiavone, P. and Ru, C. -Q., Effects of surface elasticity on an interface crack in plane deformations, Proceeding of the Royal Society of London A, Vol.467, No.7 (2011), pp. 3530-3549, DOI: 10.1098/rspa.2011.0311.

古口日出男, ナノメータサイズ弾性体の応力解析: 第 1 報, 表面応力を考慮した境界条件の定式化, 日本機械学 會論文集 A 編，Vol.58, No.555 (1992),pp.2132-2137.

Koguchi, H. and Suzuki, N., Singular stress fields in anisotropic bonded joints considering interface stress and interface elasticity, Journal of Applied Mechanics, Vol.81, No.7 (2014); DOI: 10.1115/1.4026840.

Labossiere, P. E. W. and Dunn, M. L., Stress intensities at interface corners in anisotropic bimaterials, Engineering Fracture Mechanics, Vol. 62, No.6 (1999), pp.555-575.

Muller, P. and Saul, A., Elastic effects on surface physics, Surface Science Reports, Vol.54, No.5-8 (2004), pp.157-258.

Ting, T. C. T., Anisotropic Elasticity - Theory and Application (1996), pp.164-364, Oxford University Press, New York.

Thomson, R., Chuang, T.-J. and Lin, I.-H., The role of surface stress in fracture, Acta Metallurgica, Vol.34, No.6 (1986), pp.1133-1143.

Yang, Y.Y. and Munz, D., Stress singularities in a dissimilar materials joint with edge tractions under mechanical and thermal loadings, International Journal of Solids and Structures, Vol.34, No.10 (1997), pp.1199-1216.

Zhou, X. Z., Wadley, H. N. G., Johnson, R. A., Larson, D. J., Tabat, N., Cerezo, A., Petford-Long, A. K., Smith, G. D. W., Clifton, P. H., Martens, R. L. and Kelly, T. F., Atomic scale structure of sputtered metal multilayer, Acta Materialia, 
Vol.49, No.19 (2001), pp.4005-4015.

\section{References}

Bogy, D.B., Two edge-bonded elastic wedges of different materials and wedge angles under surface tractions, Transactions of the ASME, Journal of Applied Mechanics, Vol. 38, No.2 (1971), pp.377-386.

Dempsey, J.P. and Sinclair, G.B., On the stress singularities in the plane elasticity of the composite wedge, Journal of Elasticity, Vol.9, No.4 (1979), pp.373-391.

Gurtin, M.E. and Murdoch, A.I., A continuum theory of elastic material surfaces, Archive for Rational Mechanics and Analysis, Vol. 57, No.4 (1975), pp.291-323.

Hanbucken, M., Muller, P. and Wehrspohn, R. B., Mechanical Stress on the Nanoscale, Wiley-VCHVerlag \& Co. KGaA, (2011), Germany.

Horiike, K., Ikeda, T., Matsumoto, R. and Miyazaki, N., Stress singularity analysis at an interfacial corner between dissimilar crystals and evaluation of mixed modes fracture criteria using molecular statics, Journal of the Society of Material Science, Vol.59, No.12 (2010), pp.908-915(in Japanese).

Hwu, C., Omiya, M. and Kishimoto, K., A key matrix N for the stress singularity of the anisotropic elastic composite wedges. JSME International Journal Series A, Vol. 46, No.1 (2003), pp.40-50.

Ibach, H., The role of surface stress in reconstruction, epitaxial growth and stabilization of mesoscopic structures, Surface Science Reports, Vol.29 (1997), pp.195-263.

Izumi, S., Hara, S., Kumagami, T. and Sakai, S., A method for calculating surface stress and surface elastic constants by molecular dynamics: application to the surface of crystal and amorphous silicon, Thin Solid Film, Vol. 467, No.1-2 (2004), pp.253-260.

Kim, C. I., Schiavone, P. and Ru, C. -Q., The effects of surface elasticity on an elastic solid with mode-III crack: Complete solution, Journal of Applied Mechanics, Vol.77, No.2 (2010a), DOI: 10.1115/1.3177000.

Kim, C. I., Ru, C-Q. and Schiavone, P., Analysis of plane-strain crack problems (mode-I \& mode-II) in the presence of surface elasticity, Journal of Elasticity, Vol. 104, No.1 (2010b), 397-420, DOI:10.1007/s10659-010-9287-0.

Kim, C. I., Schiavone, P. and Ru, C. -Q., Effects of surface elasticity on an interface crack in plane deformations, Proceeding of the Royal Society of London A, Vol.467, No.7 (2011), pp. 3530-3549, DOI: 10.1098/rspa.2011.0311.

Koguchi, H., Stress analysis for nano-scaled elastic materials (1st report, Formulation of boundary condition for interface with surface stress), Transactions of the Japan Society of Mechanical Engineers, Series A, Vol.58, No.555 (1992), pp.2132-2137(in Japanese).

Koguchi, H. and Suzuki, N., Singular stress fields in anisotropic bonded joints considering interface stress and interface elasticity, Journal of Applied Mechanics, Vol.81, No.7 (2014); DOI: 10.1115/1.4026840.

Labossiere, P. E. W. and Dunn, M. L., Stress intensities at interface corners in anisotropic bimaterials, Engineering Fracture Mechanics, Vol. 62, No.6 (1999), pp.555-575.

Muller, P. and Saul, A., Elastic effects on surface physics, Surface Science Reports, Vol.54, No.5-8 (2004), pp.157-258.

Ting, T. C. T., Anisotropic Elasticity - Theory and Application (1996), pp.164-364, Oxford University Press, New York.

Thomson, R., Chuang, T.-J. and Lin, I.-H., The role of surface stress in fracture, Acta Metallurgica, Vol.34, No.6 (1986), pp.1133-1143.

Yang, Y.Y. and Munz, D., Stress singularities in a dissimilar materials joint with edge tractions under mechanical and thermal loadings, International Journal of Solids and Structures, Vol.34, No.10 (1997), pp.1199-1216.

Zhou, X. Z., Wadley, H. N. G., Johnson, R. A., Larson, D. J., Tabat, N., Cerezo, A., Petford-Long, A. K., Smith, G. D. W., Clifton, P. H., Martens, R. L. and Kelly, T. F., Atomic scale structure of sputtered metal multilayer, Acta Materialia, Vol.49, No.19 (2001), pp.4005-4015. 